\title{
Communicating Climate Change: Channels, Sources, Contents and Outreach Strategies Based on China Survey
}

\author{
Yujie Li
}

\begin{abstract}
Addressing climate change can only succeed if the public realize the reality and seriousness of climate change and adjust their behavior in ways that limit emissions and promote adaptation, whereas the complexity, uncertainty and large temporal and spatial scales of the issue have caused the barriers for public understanding, which imply a strong urge for the strategic climate change communication (CCC). Public's information seeking and media use condition is a major challenge to overcome for the effective $\mathrm{CCC}$. This research has conducted an initial analysis of public's information seeking and media use based on a national random survey of public opinion on climate change in mainland China. Results from the survey shows that the Chinese respondents use TV as their most important information seeking channel, consider the science institutes as the most trusted information source, and with low attention to the environmental related news content. Statistically correlations between the aforementioned communication variables and the climate change awareness have also been tested. A number of implications for CCC strategies represented based on the results of this study.
\end{abstract}

Index Terms-China, climate change, climate change communication, public survey.

\section{INTRODUCTION}

Climate change is currently a prominent topic not only in scientific area and the media but also in public discourse both in China and worldwide. The media's extensive coverage of global warming and related issues since the end of the 1980s has created public concern [1]. The addressing of climate change can only succeed if the effective information dissemination to the general public and make them realize the climate risk and support effective action. So the importance of communicating with the public about the climate change and increasing their awareness is fully recognized by the Article 6 on Education, Training and Public Awareness of United Nations Framework Convention on Climate Change, which urges governments to develop and implement educational and public awareness programs on climate change and its effects, to ensure public access to information and to promote public participation in addressing the issue [2].

In environmental science in general and in climate change impact assessment specifically, the complexity, uncertainty and large temporal and spatial scales of the issue imply a strong urge for an adequate notion of communication [3].

Manuscript received August 27, 2014; revised January 5, 2015. This work was supported in part by China Postdoctoral Science Foundation under Grant (2014T70159).

Yujie Li is with the School of Statistics, Renmin University of China, Beijing, 100872 China (e-mail: yujie.li@ ruc.edu.cn).
Susanne Moser also pointed out that climate change is a complicated issue, with the traits of invisible causes, distant impacts, complexity, uncertainty, no quick fix, no simple fix, and no good fix and etc., which would make climate change very difficult to communicate to the general public [4].Unlike many other social issues with which the public may have first-hand experience, climate change is an issue that many come to learn about through the media. The press in some degree, as the major source of information, defines the reality of the situation for the public [5].

So communication is a critical tool in climate change response for the whole society, Informed, motivated and committed public can help the society to achieve our low carbon goals [6]. But Böhm and Pfister reported that, possibly due to these media, knowledge about climate change among layperson in the United States, as well as in Europe and South America, is vague and contains misunderstandings. Still, people may not always realize this vagueness [7]. For the better effects, we need to find the effective communication strategies, the CCC questions such as the public's information seeking channels and media use, trusted information sources, and attention to climate change news, etc., therefore, is worthy of survey and in-depth discussion.

Regarding channels the public access to climate change information, many polls have found that television and daily newspapers are the primary channels in what are conventionally regarded as 'developed nations'. In 'developing countries' such as in Africa more specifically in rural areas, radio has been a principle medium through which climate change news is communicated [8], [9].

Peter Weingart et al., analyzed the communication about global warming among science, politics, and the media in Germany from 1975 to1995and found that there were three separate discourses on climate change in science, politics, and the mass media, which could entail the risks of communication and public's confusion about the issue and distrust the information sources [10]. Eva-Lotta Sundblad et al., investigated experts, journalists, politicians, and laypersons in Sweden and found that the even though experts presented the highest level of knowledge and confidence in their knowledge and have direct access to information in their own discipline, other groups in society, politicians and public included, are more dependent on information mediated by journalists via mass media [11]. In US, survey findings shows that Americans trust the scientists the most and the corporation listed as the final in trust order [12]. In Australia, Authoritative institutions (science and education) were the most trusted sources of climate change information, but the public remained skeptical about some of the information derived from even these sources [13].

As the public's attention to climate change information, 
one survey shows that only $12 \%$ Americans pay a lot attention to the information about global warming, while $18 \%$ respondents without attention to the information [12]. In the Pew Research Center's 2013 policy priorities survey, just $28 \%$ Americans say dealing with global warming is a top priority for the president and congress this year while $85 \%$ claims strengthening economy is a top priority [14].

Even though abundant literature about the CCC in developed countries can be found and a variety of information about their public's information seeking and media use can be obtained, targeted strategies have been adopted thereafter to effectively communicate the information to public, little is known about Chinese.

China, the world' $\mathrm{s}$ biggest $\mathrm{CO}_{2}$ emitter and the largest developing country with a large population, which is currently facing the unique challenges of developing its economy, eradicating poverty and improving the people's livelihoods, as well as actively tackling climate change [15]. So to investigate how the Chinese public obtains and responds to climate change information, consequently, becomes an important question to ask as we seek to understand their awareness and knowledge about climate change. In this study, we draw upon a nationally representative survey of Chinese public opinion on climate change, in which the aforementioned communication questions were involved in, so further study about the relationship between awareness and communication would be explored.

\section{SURVEY}

A national survey was carried out by China Center for Climate Change Communication from July to September 2012 in mainland China. Since the popularity of landline and mobile phones in China, so the survey was conducted by computer-assisted telephone interviews (CATI). Throughout the process, less than $5 \%$ of the respondents chose 'unclear of the question' or 'no answer' as their responses to some questions. In order to better demonstrate data results, percents of those provided these two answers were not included in the analysis.

The population was stratified into 336 layers, based on the 332 prefecture-level units in mainland China (including 284 prefecture-level cities, 15 districts, 30 prefectures, 3 areas and 4 municipalities directly under the central government). The number of samples for each layer is in accordance with the population ratios of locations. With random selection of the last few digits of landline and mobile phone numbers and a ratio of 40:60 between the two types of telephones, 4,169 valid samples were included in the CATI of the survey and all samples are scientifically random.

The questionnaire survey, comprising majority of questions were employed to build a comprehensive picture of Chinese perception of climate change including personal beliefs, threat, concern, policy support and personal actions. In addition, CCC questions were specially included in last section to better describe the public's information seeking and media use, which would be our focus in this paper. SPSS software was used to explore and highlight any statistical correlations between the different variable, and produce graphs and tables to present the results.

\section{RESULTS AND DISCUSSION}

\section{A. Information Seeking Channels}

The majority of respondents could access information related to climate change through various channels shown in Table I, included in which TV $(93.8 \%)$, cell-phone $(66.1 \%)$ and internet $(65.0 \%)$ are the most popular ones. Family and friends are also information seeking channels, which counted for $54.5 \%$ among the respondents. Newspaper, mobile media, broadcast and magazine these traditional media also have some effect, but less strong than new media, in terms of coverage. In addition, some respondents can access information related to climate change through propaganda activities, firsthand experience, education and movies.

TABLE I: CLIMATE CHANGE INFORMATION SEEKING CHANNELS

\begin{tabular}{ll}
\hline \hline Information seeking channels & Percentage \\
\hline TV & $93.8 \%$ \\
Cell phone & $66.1 \%$ \\
Internet & $65.0 \%$ \\
Family and friends & $54.5 \%$ \\
Newspaper & $49.0 \%$ \\
Mobile media & $38.0 \%$ \\
Radio & $33.6 \%$ \\
Magazine & $30.1 \%$ \\
Propaganda activities & $29.0 \%$ \\
First-hand experience & $2.4 \%$ \\
Education & $1.5 \%$ \\
Movies & $0.1 \%$ \\
Total & $463.0 \%$ \\
\hline \hline
\end{tabular}

Table II presents a statistically significant difference between respondents in urban and rural China regarding channels of seeking climate change information, with 4.914 average channels access to the climate change information for urban Chinese compared 4.254 of rural residents. Most channels coverage in urban areas are higher than rural areas except the TV, family and friends (interpersonal communication) that also the two predominant communication method in rural China.

TABLE II: INFORMATION SEEKING CHANNELS (RESIDENTIAL LOCATION)

\begin{tabular}{lll}
\hline \hline Channels & Urban & Rural \\
\hline TV & $93.2 \%$ & $94.7 \%$ \\
Internet & $72.2 \%$ & $55.3 \%$ \\
Cell phone & $67.2 \%$ & $64.7 \%$ \\
Newspaper & $55.9 \%$ & $39.8 \%$ \\
Family and friends & $55.6 \%$ & $53.1 \%$ \\
Mobile media & $41.3 \%$ & $33.6 \%$ \\
Radio & $35.9 \%$ & $30.6 \%$ \\
Magazine & $34.7 \%$ & $24.0 \%$ \\
Propaganda activity & $31.3 \%$ & $26.0 \%$ \\
Others & $4.1 \%$ & $3.6 \%$ \\
Total & $491.4 \%$ & $425.4 \%$ \\
\hline \hline
\end{tabular}

Table III presents a statically correlation between the climate change information seeking channels and the personal awareness on climate change (four levels) of Chinese 
respondents, the more channels they are access to the climate change information, the high self-reported personal awareness of this issue.

TABLE III: INFORMATION SEEKING CHANNELS AND PERSONAL AWARENESS

\begin{tabular}{ll}
\hline \hline Personal awareness & $\begin{array}{l}\text { Information seeking } \\
\text { channels }\end{array}$ \\
\hline Know a lot & 5.4 \\
Know something & 4.9 \\
Know a little & 4.6 \\
Never heard & 3.6 \\
$\mathrm{P}$ & 0 \\
\hline \hline
\end{tabular}

\section{B. Trust in Information Sources}

In order to compare the level of trust in six different climate change information sources, we put 1, 2, 3 and 4 points to the choices of 'highly trust', 'relatively trust', 'do not trust much' and 'do not trust' respectively. Table IV shows that the respondents trust information published by science institutes the most, and the government, followed by media, family and friends, with non-governmental organizations (NGOs) and enterprises well behind.

TABLE IV: TRUST IN DIFFERENT INFORMATION SOURCES

\begin{tabular}{lll}
\hline \hline Sources of Information & Mean Value & Standard Variance \\
\hline Science Institutes & 3.3 & 0.7 \\
Government & 3.2 & 0.7 \\
News Media & 3.0 & 0.7 \\
Family and Friends & 2.7 & 0.8 \\
NGOs & 2.2 & 0.9 \\
Enterprises & 2.2 & 0.8 \\
\hline \hline
\end{tabular}

There is also a difference of trusted information sources between the urban and rural respondents shown in Table V, the urban residents with more trust in NGOs, however, are less trusting of government and science institutes compared to the rural respondents.

TABLE V: TRUST IN DIFFERENT IN INFORMATION SOURCES (RESIDENTIAL

\begin{tabular}{llll}
\multicolumn{4}{c}{ LOCATION) } \\
\hline \hline \multirow{2}{*}{ Location } & $\begin{array}{l}\text { Science } \\
\text { Institutes }\end{array}$ & Government & NGOs \\
\hline Urban & 3.2 & 3.1 & 2.3 \\
Rural & 3.3 & 3.2 & 2.2 \\
\hline \hline
\end{tabular}

Table VI presents that the gender difference, male with lower trust in all kinds of information sources compared to the female respondents, especially they distrust the enterprises.

TABLE VI: TRUST IN DIFFERENT IN INFORMATION SOURCES (GENDER)

\begin{tabular}{lllll}
\hline \hline Gender & Science & Government & $\begin{array}{l}\text { Family and } \\
\text { Friends }\end{array}$ & Enterprises \\
& Institutes & & 2.7 & 2.3 \\
\hline Female & 3.3 & 3.2 & 2.7 & 2.2 \\
Male & 3.2 & 3.1 & & \\
\hline
\end{tabular}

\section{Attention to Environment (Climate Change) Related} News

Table VII shows that in general, social news draws the highest level of attention of the respondents, at $29.3 \%$, followed by economic news $(25.2 \%)$, political news $(15.3 \%)$ and entertainments $(11.5 \%)$, with environment-related news $(9.2 \%)$ a more distant five.

TABLE VII: ATTENTION TO SPECIFIC FORMS OF NEWS

\begin{tabular}{ll}
\hline \hline Information access channels & Percentage \\
\hline Social news & $29.3 \%$ \\
Economic news & $25.2 \%$ \\
Political news & $15.3 \%$ \\
Entertainments & $11.5 \%$ \\
Environmental news & $9.2 \%$ \\
Science\& Technology news & $8.0 \%$ \\
Celebrity & $1.5 \%$ \\
\hline \hline
\end{tabular}

Table VIII represents a statically correlation between level of concern about climate change and attention to environmental related news. The respondents who are very concerned about the climate change with highest attention to environmental related news, then the different level of concern followed by the corresponding attention in environmental related news.

TABLE VIII: LEVEL OF CONCERN AND ATTENTION TO ENVIRONMENTAL NEWS

\begin{tabular}{ll}
\hline \hline Level of concern & Attention to environmental \\
about climate change & news \\
\hline Very concerned & $14.2 \%$ \\
Somewhat concerned & $7.3 \%$ \\
Not much concerned & $4.0 \%$ \\
Not concerned at all & $2.1 \%$ \\
\hline \hline
\end{tabular}

\section{CONCLUSIONS}

This study has conducted an initial analysis of Chinese public's climate change access information channels, trusted information sources and attention to environmental related news content based on the national survey. We use a unique survey that asks the Chinese respondents directly about their attitudes of CCC questions for the first time in China. The major findings showed that some communication strategies need to be used to better disseminate the climate change information to the general public, but these strategies can only succeed if they are in accordance with the aforementioned characteristics of Chinese respondents in terms of information seeking and media use.

We find that there is a statistically correlation between the public's climate change information seeking channels and their level of awareness, so it might mean the more channels covered the public, the higher awareness to be raised about this issue. We also observed that the vast majority have access to obtain the climate change information, among all the information channels, the traditional mass media, such as the television and newspapers, were almost ubiquitous for the CCC and which are still the predominant information seeking channels for Chinese respondents, but we should notice that the new media such as the cell phone and internet also with a large proportion in the current CCC media ecology and which could become the major media in the future considered the 
current huge internet population in China. A latest report shows that China had 632 million internet users and 527 million mobile internet users, and the percentage of Chinese users accessing the internet via mobile grew to 83.4 percent as of June 2014, for the first time surpassing the percentage of users who access the internet via PCs (80.9 percent) [16], which gives an implication that the cell phone has become the most important information seeking channel for Chinese, so does the CCC. In addition to the mass communication channels, other interpersonal communication (family and friends),intrapersonal communication (personal experience) and group communication (education) channels also need to be focused and widely used especially in rural China where the new media is relatively underdeveloped and the information seeking channels are less than the urban areas, while those living in these areas often being described as the ones who are "closest to the manifestations of climate change" and "the first line of participation" are likely to accept the aforementioned channels [17].

This survey shows that science institutes (scientists) were generally conceived to be a much more trusted source of climate change information than any other sources. The complexities of the climate change issue, as well as the scientific uncertainties involved and the far distance from their daily life could be used to explain this phenomenon, the science institutes are identified as holding the most credibility because they are the authoritative institutions with professional knowledge about this issue. Whereas actually in China, the voice of science community always keep consistent with the government in the climate change field, so in some degree these two bodies disseminate the climate change information with one accord and make the government become the predominant information sources, so it's no wonder that their second trusted sources of information on climate change is government, unlike other researches undertaken in developed countries, their participants were found to be deeply mistrustful of politicians and government as reliable sources of information about climate change [18]. An important implication for the CCC is to keep the independent discourse of science and increase the interaction between the science and the public, for example, launching more activities to keep the dialogue, citing more scientific researches to train and education the public and so on. We also find that in general the Chinese respondents have limited trust in NGOs and enterprises these two information providers, but considered the demographic factors such as residential location and gender, CCC for segmenting audiences also need to be emphasized, for example, the urban respondents trust NGOs more than the rural with the rapid development of international NGOs (Greenpeace China, World Wildlife Fund China, Friends of Nature and Oxfam Hong Kong etc.) and their flourishing activities focusing on climate change in urban China. Therefore, the use of CCC information sources can vary among the different audiences as needed.

We also find the Chinese respondents are highly attentive to social news, then political, economic and entertainments news, and all higher than the attention to the environmental news. Many Chinese perceive climate change as a distant problem that will primarily affect future generations of people in other countries. In turn, climate change is consistently ranked as a relatively low public priority, compared to a range of other national issues. So it requires the climate change communicators to frame messages in ways that are consistent with the attention, interests and beliefs of the audience. For example, a recent effort to attract the attention of Chinese about climate change and related air pollution issue by using the public health frame under the condition of severe haze hit in the China big cities, which has connected the addressing of climate change with the increase of certain diseases and caused a general concerning about this issue. Personal experience of climate change leads people to become convinced of its reality, so pointing out concrete ways in which public have personally experienced climate change may be the most useful strategy if we want to focus the Chinese's attention on climate change.

\section{ACKNOWLEDGMENT}

I gratefully acknowledge the support by the China Center for Climate Change Communication and School of Statistics, Renmin University of China.

\section{REFERENCES}

[1] P. Weingart, A. Engels, and P. Pansegrau, "Risks of communication discourses on climate change in science, politics, and the mass media," Public Understanding of Science, vol. 9, pp. 261-283, 2000.

[2] UNFCCC Article 6. Education, training and public awareness. [Online]. Available: http://unfccc.int/essential_background/convention/background/items/ 1366.php

[3] I. Jürgens, "Climate change and the communication between scientists andstakeholder," M.S.thesis, Dept. Enviromental Science, Lund Univ., Sweden, 2001

[4] S. C. Moser, "Communicating climate change: History, challenges, process and future directions," Wiley Interdisciplinary Reviews-Climate Change, vol. 1, pp. 31-53, 2010.

[5] X .Q. Zhao, "Media use and global warming perceptions: A snapshot of the reinforcing spirals," Communication Research, vol. 5, pp. 698-723, 2009.

[6] United Nations Environment Programme. (2005). Communicating sustainability: How to produce effective public campaigns. [Online]. Available:

http://www.unep.fr/shared/publications/pdf/DTIx0679xPA-Communi catingEN.pdf

[7] G. Böhm and H. Pfister, "Mental representation of global environmental risks," Research in Social Problems and Public Policy, vol. 9, pp. 1-30, 2001.

[8] Human Development Report. (2007/2008). Fighting climate change: Human solidarity in a divided world. [Online]. Available: http://hdr.undp.org/fr/rapports/mondial/rdh2007-8/documents/Boykof f,\%20Maxwell\%20and\%20Roberts,\%20J.\%20Timmons.pdf

[9] P. Luganda, "Communication critical in mitigating climate change in Africa," presented at the Open Meeting of the International Human Dimensions Programme, Bonn, Germany,October, 2005.

[10] P. Weingart, A. Engels, and P. Pansegrau, "Risks of communication: discourses on climate change in science, politics, and the mass media," Public Understanding of Science, vol. 9, pp. 261-283, 2000.

[11] E. Sundblad, A. Biel, and T. Garling, "Knowledge and confidence in knowledge about climate change among experts,journalists, politicians, and laypersons," Environment and Behavior, vol. 41, pp. 281-302, 2009.

[12] A. Leiserowitz. Global Warming's Six Americas 2009. (June 2009) An Audience segmentation analysis. [Online]. Available: http://environment.yale.edu/climate-communication/files/SixAmerica s2009. pdf

[13] H. Bulkeley, "Common knowledge? Public understanding of climate change in Newcastle, Australia," Public Understanding of Science, vol. 9, pp. 313-333, 2000.

[14] Pew Research Center. 2013 policy priorities survey. [Online]. Available: 
http://www.pewresearch.org/key-data-points/climate-change-key-data -points-from-pew-research/

[15] China's policies and actions for addressing climate change. (Octorber, 2013). [Online]. Available: http://www.ndrc.gov.cn/gzdt/W020131107539684396470.pdf

[16] China Internet Network Information Center. (August 2014). The 34th statistical report on internet development in China. [Online]. Avilable http://www.cnnic.net.cn/hlwfzyj/hlwxzbg/hlwtjbg/201407/P0201407 21507223212132.pdf

[17] S. Manandhar, D. S. Vogt, S. R. Perret, and F. Kazam, "Adapting cropping systems to climate change in Nepal: A cross-regional study of farmers' perception and practices," Regional Environmental Change, vol. 2, pp. 335-348, 2010.

[18] I. Lorenzoni and N. F. Pidgeon, "Public views on climate change:european and USA perspectives," Climatic Change, vol. 77, pp. $73-95,2006$

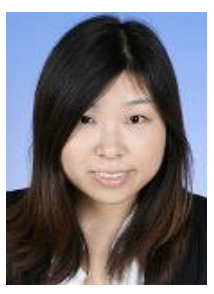

Yujie Li was born in China on December 28, 1983. She holds a B.A. degree in English journalism from Sichuan International Studies University, Chongqing, China, 400031. She got Ph.D. and M.A. degrees in journalism from Journalism and Communication School at Renmin University of China, Beijing, China, 100872

She is a lecturer and postdoc researcher at the School of Statistic at Renmin University of China and also the deputy director of China Center for Climate Change Communication which is the first research program specializing in the climate change communication in China. She was a visiting scholar of Yale University and University of Missouri. Now she is also working as visiting researcher at the National Center for Climate Change Strategy and International Cooperation, China.

Dr. Li's research areas are in climate change communication, public survey, climate change policy, and the theory and history of journalism research. 